\author{
WHEN LIBERAL POLICIES \\ REFLECT EXTERNAL SHOCKS, \\ WHAT DO WE LEARN?
}

\author{
Leonardo Bartolini \\ Allan Drazen
}

Working Paper 5727

\author{
NATIONAL BUREAU OF ECONOMIC RESEARCH \\ 1050 Massachusetts Avenue \\ Cambridge, MA 02138 \\ August 1996
}

Research for this paper began when L. Bartolini was in the Research Department of the IMF and A. Drazen was visiting the Research Department of the IMF and the Policy Research Department (PRDMG) of the World Bank. A. Drazen acknowledges support from NSF grant No. SBR-9413355. We thank C. Cottarelli, G.M. Milesi-Ferretti, R. Clarida, D. Weil, seminar participants at the Board of Governors of the Federal Reserve, Boston College, Columbia University, the Federal Reserve Banks of Atlanta and New York, the Hebrew University of Jerusalem, the University of Maryland, University of Texas at Austin, the World Bank, the 1996 Meeting of the Econometric Society, the 1996 NBER Summer Institute on International Finance and Macroeconomics, and especially two discussants, A.K. Rose and A. Velasco, for many useful comments, and N. Gunaratne for technical assistance. Errors and omissions are our responsibility. This paper is part of NBER's research program in International Finance and Macroeconomics, NBER's project on International Capital Flows and was presented at the NBER conference "Universities Research Conference on the Determination of Exchange Rates." We are grateful to the Center for International Political Economy for the support of this project. Any opinions expressed are those of the authors and not those of the Federal Reserve System or the National Bureau of Economic Research.

(C) 1996 by Leonardo Bartolini and Allan Drazen. All rights reserved. Short sections of text, not to exceed two paragraphs, may be quoted without explicit permission provided that full credit, including $(\mathcal{O}$ notice, is given to the source. 


\title{
WHEN LIBERAL POLICIES \\ REFLECT EXTERNAL SHOCKS, WHAT DO WE LEARN?
}

\begin{abstract}
We present a model where policies of free capital mobility can signal governments' future policies, but the informativeness of the signal depends on the path of world interest rates. Capital flows to "emerging markets" reflect investors' perception of these markets' political risk. With low world interest rates, emerging markets experience a capital inflow and engage in a widespread policy of free capital mobility; with higher rates, only sufficiently committed countries allow free capital mobility, whereas others impose controls to trap capital onshore, thus signaling future policies affecting capital mobility. These predictions are consistent with the recent experience of capital flows and policies affecting capital mobility in developing countries.
\end{abstract}

Leonardo Bartolini

Federal Reserve Bank of New York

Federal Reserve PO Station

New York, NY 10045

\author{
Allan Drazen \\ Center for International Economics \\ 4118 Tydings Hall \\ University of Maryland \\ College Park, MD 20742 \\ and NBER \\ DRAZEN@ECON.UMD.EDU
}




\section{Introduction}

If a country liberalizes capital movements, it is often viewed as signaling its commitment to policies favorable to investment; to the extent it can differentiate itself from other countries competing for funds, investors may respond favorably. What are individual countries' incentives to allow free capital mobility, when such policy is widespread? And what is the information contained in a single country's liberal policy, when most countries liberalize in response to external developments?

In the late 1980s and early 1990s most Latin American and many other developing countries significantly liberalized their economies. At the same time capital poured in, the inflow from industrial countries rising from about $\$ 45$ billion per year in $1985-88$, to above $\$ 200$ billion in $1993 .^{2}$ Despite its role in attracting foreign capital, financial liberalization was not the only factor responsible for these massive inflows. Calvo, Leiderman, and Reinhart $(1993,1994)$, for instance, provide evidence that external factors--mainly, the U.S. economic slowdown and fall in interest rates--could explain perhaps half of the inflow experienced by Latin American countries in the 1989-1992 period (see also Chuhan, Claessens, and Mamingi, 1993). Hence, both external and domestic factors--less attractive investment opportunities in industrial countries, and stronger commitment to free markets in many developing countries--led investors to search for higher returns in Latin America and East Asia.

Beginning in late-1993, the ongoing U.S. expansion and European recovery led to a reversal of capital flows between industrial and developing countries, while the supposed firm commitment of some emerging economies to liberal policies was also suddenly called into question. Capital flows to developing countries fell by one-fifth from 1993 to 1994 , with the

\footnotetext{
${ }^{2}$ See IMF (1996) for summary data on international capital flows.
} 
February 1994 rise in U.S. interest rates often viewed as the turning point. At the same time, while some countries stayed the course to liberalization, others which had earlier liberalized (for example, Venezuela, Brazil, Ecuador, and Nigeria) resorted to re-imposing capital controls or to tightening existing regulations and delaying announced liberalization plans. ${ }^{3}$

Emerging markets' experience with capital account policies since the late-1980s motivates a search for a more structural link between macroeconomic developments in industrial countries and policies affecting capital mobility in developing countries. To this end, we compiled data on capital controls from the IMF's annual survey of Exchange Arrangements and Exchange Restrictions from 1970 to 1994 , following the methodology of Epstein and Schor (1992) and Grilli and Milesi-Ferretti (1995), among others. We defined three dummy variables, each taking a value of one when a country was classified in the survey as restricting payments for capital transactions, enforcing multiple exchange rates, or restricting repatriation of export proceeds in a given year, respectively. Adding up over countries, and normalizing by (three times) the number of countries, we constructed an index of capital controls in developing countries, ranging between zero and one, roughly capturing the pervasiveness of the most common restrictions on capital mobility. The index takes a value of one in any year if all countries enforce all three types of restrictions in that year, and a value of zero if no such restriction is imposed anywhere in that year. Our sample includes 73 developing countries surveyed from 1970 to 1994 (those for which there is complete data for the period, out of 162 developing countries). We also constructed a measure of real (ex post) returns to capital in industrial countries by deflating average long-term

\footnotetext{
${ }^{3}$ In the event, the previous meteoric rise of many emerging stock markets was matched by an equally sharp fall. As one wag put it, it was at this point that he learned what "emerging markets" really meant, when he discovered how difficult it was to emerge unscathed.
} 
interest rates in the G-7 countries with average GDP inflation rates.

Figure 1 plots the resulting capital controls index against the G-7 and U.S. long-term real interest rates. The data underlying the plot is obviously crude, and the dynamics in mid-sample strongly reflect the debt crisis of the early 1980s. Nevertheless, the correlation between the capital controls and rate of return indices is striking. ${ }^{4}$ A 25 -observation, time-series regression of the capital controls index on the G-7 interest rate gave an $r^{2}$ of .65 and a $t$-statistic of 7: industrial countries' interest rates appear to be important determinants of developing countries' liberalization decisions. ${ }^{5}$ The data also suggest a more general pattern of widespread liberalizations and massive inflows, subsequent policy reversals, and investors' belated pledge to greater selectivity the next time around: massive capital flows to developing countries in the late 1970s were also associated with extensive liberalization in these countries; and the ensuing debt crisis was also accompanied by a resurgence of restrictive policies.

In this paper we present a signaling model of policy choices that rationalizes the observed link between world interest rates (and external macroeconomic events, more generally) and policies affecting capital mobility in small open economies. When used to interpret the events of the early-80s and early-90s, our model suggests a different view from the two views most frequently offered of these episodes. According to one of these views, the rush of capital into

${ }^{4}$ Among other shortcomings, our capital control index does not measure the intensity or effectiveness of controls, nor does it distinguish between controls on inflows and outflows (though restrictions are mainly on outflows). Similarly, nominal interest rates should be deflated by expected (rather than actual) inflation. To the extent that actual inflation has typically fallen short of expected inflation in most industrial countries since the early 1990s, the appropriate real rate of return series would fall in this period below the ex post series plotted in Figure 1. Rapid progress toward liberal markets in late-sample may also reflect structural changes not captured in our simple empirical model, such as secular erosion in the effectiveness of capital controls.

${ }^{5}$ Regressions using short-term rates and similarly constructed indices of capital restrictions gave very similar results. All data are available from the authors upon request. 
emerging markets was less than fully rational to begin with, reflecting instead a herd mentality that led most investors to bet on anything exotic, without bothering to distinguish sound from unsound investment opportunities. From this viewpoint, getting burned ex post was the natural outcome of investors not being sufficiently discriminating ex ante. An alternative view is that the dissimilar experience in bad times of countries that were similar in good times reflects countryspecific events or policy mistakes (such as Venezuela's mishandling of its financial crisis in 1994, or Mexico's unflinching exchange rate policy in 1992-93), rather than investors' irrational attitudes. Hence, it was rational to view most emerging markets as similar ex ante, but specific shocks made them dissimilar ex post, causing some of them to falter on their path to reform.

Though both these views may contain elements of truth, neither is fully persuasive: the first because appeals to irrationality prove satisfying to few economists; the second because the evidence presented in Figure 1 (reinforced by that of Calvo, Leiderman, and Reinhart for the recent Latin American episode) suggests that the "similarity" between many emerging markets may have been primarily in the external situation they faced. In this paper we argue that the supposed indiscriminate character of periodic inflows into emerging markets, subsequent selective outflows, and accompanying policy reversals, may be indicative neither of governments' or investors' irrationality, nor of (some of the) recipient countries' bad luck. They may simply reflect investors' optimal response to available information: when a common external shock causes widespread adoption of liberal policies, it also reduces the information content of the policy itself. Lacking information to discriminate, investors invest in all markets where policies favorable to investment have been implemented, only to discover the weak commitment of some countries to such policies, in the face of a subsequent adverse shock.

Our argument can be applied to structural reform in general. In deciding on structural 
policies, governments trade off costs and benefits, a trade-off that may depend on external circumstances. "Good" times reduce the cost of reforms and cause their widespread adoption; "bad" times induce only sufficiently motivated governments to reform. If a favorable environment leads many countries to reform, investors may be unable to distinguish governments truly committed to reform from those likely to renege on them in less favorable times, and conversely when the environment is so adverse that no government implements reforms. Away from the two extremes, some--but not all--governments will engage in structural reforms at any given time, depending on the relevant trade-off between costs and benefits. The evolution of this trade-off affects the information revealed to investors on the likely course of future policies in different countries, and provides a channel for investment hysteresis. This channel, the revelation of "innate" characteristics due to the changing external environment, is quite separate from those of adjustment costs or multiple equilibria emphasized in previous research.

For concreteness, we develop this argument in a simple model of capital controls, though we are well aware that balance of payment reform was only one element in the package of reforms undertaken in recent years in many developing countries. In our model, governments' attitudes toward capital mobility differ across countries and are imperfectly observable by investors. Low world interest rates induce investment into emerging markets and promote free capital mobility, by reducing the cost of this policy. A sufficiently low interest rate causes all emerging countries to open their capital account, makes such policy uninformative of host governments' attitudes toward free capital mobility, and causes too much capital to be invested in countries likely to impose controls in the future.

While our model shares many features with other signaling models, our analysis displays the uncommon--and crucial--feature that the nature of the equilibrium (in particular, whether it is 
of a pooling or a separating type) varies over time in response to external shocks (an interest rate shock in our case). In our model, investors know the process driving interest rates and incorporate potential changes in the type of equilibrium in their investment decisions.

The paper is organized as follows. A simple signaling model, where investment and capital control policies evolve endogenously in response to world interest rate shocks is presented in Section 2 and solved in Section 3. Sections 4 and 5 discuss the equilibrium and the effect of interest rate shocks. Section 6 concludes, while the Appendix contains technical details.

\section{The model}

Our model extends the two-period model of capital controls of Bartolini and Drazen (1995) to a full intertemporal model, relying on a somewhat more general model of governments' costs and utility of controls, and allowing for stochastic interest rates (on which government and investors have the same information). Motivated by the discussion of Section 1, the model incorporates a link between world interest rates and capital control policies in small open economies, and differs from previous models of capital controls in a number of respects. First, controls evolve endogenously from a government's intertemporal choice problem in the face of potential capital flows, rather than being imposed as an exogenous constraint. ${ }^{6}$ Second, in contrast with the traditional symmetric modelling of controls on inflows and outflows, our model recognizes that real-world controls are typically asymmetric: stricter either on inflows or, more frequently, on outflows. By modelling external shocks as outcomes from a stochastic process, the model allows for endogenous switches in the type of equilibrium realized in each period.

${ }^{6}$ The implication of exogenous liberalizations for capital flows have, of course, been already studied in the literature. See, for instance, Obstfeld (1986) and Bacchetta (1992). 
The possibility that different equilibria may be realized in each period is recognized by all agents, and is reflected in equilibria realized earlier on.

Consider a $T$-period model of a small open economy, where a homogeneous good $Y_{t}$ is produced at time $t$ with onshore capital $K_{t}$ using a concave technology $Y_{t}=f\left(K_{t}\right)$ that satisfies the standard Inada conditions (other domestic factors that are internationally immobile are normalized to unity). In each period, the supply of capital in the world market is perfectly elastic at the interest rate $r_{1}$. In this market, a large number of profit-maximizing, risk-neutral investors allocate capital between onshore and offshore investment. Absent adjustment costs, and assuming capital to be liquidated at the end of period $T$, the returns to physical and financial capital are equalized and we shall make no distinction between the two.

The government derives utility from domestic capital in each period, as described by a concave function $W\left(K_{t}\right)$. This utility may reflect interest in residents' utility from GDP, utility from public expenditure financed from capital taxation, etc. ${ }^{7}$ Single-period utility is discounted at the rate $\rho$ and also satisfies the standard Inada regularity conditions.

Governments differ in the cost they attach to imposing capital controls. This heterogeneity may reflect differences in the value attached to residents' ability to diversify risk internationally, different commitment to free markets, etc. Since our results do not depend on the specific source of this cost, but only on investors having incomplete information about them, we model this cost as simply as possible. We begin by assuming that the government assigns a one-time cost $x \in(0, \infty)$ to imposing controls the first time it imposes controls, and no further cost thereafter,

${ }^{7}$ The government's welfare may also depend on arguments other than the stock of domestic capital. Therefore, this welfare function is best interpreted as an indirect utility function, other variables having been set optimally at each $K_{t}$. 
and refer to $x$ as a government's type. (The cost $x$ does not include the reputational cost of controls, which is central to our analysis and is discussed explicitly below.) The assumption of a one-time cost can be rationalized by interpreting $x$ as the cost of breaking an international agreement to allow free capital mobility, the cost of face-loss, or other costs incurred when reneging on a policy commitment (as in Rogoff, 1987, for instance, where governments assign a one-time cost to breaking a commitment to zero inflation). In our model, this assumption plays the role of making capital controls permanent once imposed, thereby greatly simplifying the exposition, and allowing us to highlight the model's main insight. In a later section, however, we discuss how the solution is modified in a more general setting.

We model asymmetric information about $x$ by assuming that only the government is informed about $x$ as of time zero, while investors must infer this characteristic based on the observation of actual policies and their prior cumulative probability distribution, $\mathrm{G}(x)$, over types.

Table 1 summarizes the timing of the model. The initial stock $K_{0}$ and distribution $\mathrm{G}(x)$ describe the initial state. At the beginning of each period, both the government and investors are informed of the current world interest rate $r_{t}$, as drawn (independently, for simplicity) from the cumulative distribution $\mathrm{M}(r)$. After observing $r_{t}$, the government announces the financial regime prevailing in the current period. (We use the dummy $c_{t}$ to denote the regime prevailing in period $t$, letting $c_{t}=\mathrm{F}$ and $c_{t}=\mathrm{R}$ denote free and restricted mobility, respectively.) If controls are imposed at $t$, the end-of-period stock of domestic capital, $K_{t}$, is constrained to be at least as large as at the beginning of the period: $K_{t} \geq K_{t-1}{ }^{8}$ After the period $t$ regime has been

${ }^{8}$ We focus exclusively on controls on capital outflows. Given the government's taste for domestic capital, there are no incentives to impose controls on inflows in this model. We also focus on the case in which capital controls are fully effective. The tendency for capital controls to lose effectiveness in the long run (see, for instance, Mathieson and Rojas-Suárez, 1993, for a 
announced, investors choose $K_{t}$ accordingly, and collect the resulting returns. ${ }^{9}$

In the next section we solve this model recursively backward, and derive a unique equilibrium for each period $t$ given the solution for period $t+1$. Since the solution is somewhat technical, however, it may be useful to summarize its intuition here.

Consider investment and capital controls decisions in a single country. In the final period $T$, if the host government does not impose controls, the marginal product of onshore capital is equalized to the current world interest rate, yielding $K_{T}=\left(f^{\prime}\right)^{-1}\left(r_{T}\right)$. If controls are imposed, instead, the domestic capital stock equals the larger of the unconstrained stock and the previous period's stock, $K_{T-1}$. Thus, the actual capital stock depends on the regime chosen by the government for this period. To examine this policy, first observe that a standard backward recursion argument implies that once a government imposes controls in any period, it will certainly impose controls until period $T .^{10}$ On the other hand, the optimal period $T$ policy of

discussion) can be accommodated by re-writing the capital control constraint as $K_{t} \geq(1-\delta) K_{t-1}$, where $\delta$ captures the rate at which controls can be circumvented in each period. The analysis then remains qualitatively unchanged, as long as $\delta<1$, i.e., as long as controls are at least partially effective in the short run. However, a further bias toward liberalization would be induced by the assumed leakiness of controls. In the limit, as $\delta \rightarrow 1$, controls become fully ineffective, and all incentives to impose them vanish.

${ }^{9}$ For simplicity, we abstract from other policies often undertaken in conjunction with capital controls, policies that usually include taxation of domestic capital, interest rate ceilings, and other forms of "financial repression" that penalize foreign investors in addition to capital controls (see Giovannini and De Melo, 1993, for a discussion, as well as for evidence in support of the joint use of capital controls and financial repression in developing countries). As in Bartolini and Drazen (1995), these motives could be captured by allowing the host government to levy a tax on onshore capital, assuming that tax revenues are transformed into public expenditure, and letting government's utility be increasing in the supply of public goods.

${ }^{10}$ Since a government that has already imposed controls faces no further cost from doing so again at $T$, it certainly imposes controls at $T$, thereby maximizing $K_{T}$ at no cost. But this implies that no cost would be incurred also at $T$-1, if controls have been already imposed in the past: neither a direct nor a reputational cost (since the government is already known to use controls for sure at $T$ ). Then controls are always imposed at $T-1$, and so on, recursively backward. 
governments that have not previously imposed controls is summarized by the type $\hat{x}_{T}=\hat{x}_{T}\left(K_{T-1}, r_{T}\right)$ that is indifferent between imposing controls (yielding utility $W\left(K_{T} \mid \mathrm{R}\right)-x$ ) and not imposing controls (yielding $\left.W\left(K_{T} \mid \mathrm{F}\right)\right)$. Hence, $\hat{x}_{T}=W\left(K_{T-1}\right)-W\left(\left(f^{\prime}\right)^{-1}\left(r_{T}\right)\right.$ ). Governments with cost $x<\hat{x}_{T}$ impose controls, those with cost $x \geq \hat{x}_{T}$ allow free mobility of capital, unless they have imposed controls in a previous period, in which case they impose controls also at $T$.

The equilibrium in periods $t<T$ has similar properties. In comparing onshore and offshore returns, however, investors must consider the likelihood that controls may be imposed in the future. If controls have been observed in the past, this likelihood is, trivially, equal to one. If, instead, free capital mobility has prevailed until $t$, the likelihood of future controls depends on the residual uncertainty over government types, as summarized by the range of "possible" types, those that may have carried out a policy of free capital mobility before $t$. This range evolves, as specified below, as a function of the external macroeconomic environment.

The government's optimal policy in period $t$ is also similar to that for period $T$, and is summarized by the cut-off type $\hat{x}_{t}$ that is indifferent between imposing and not imposing controls at $t$, conditional on it not having previously imposed controls. Types $x$ below the cut-off type impose controls at $t$ and thereafter; types above the cut-off type impose controls at $t$ only if they have already imposed controls in the past.

In equilibrium, and focussing on the case where the commitment to free mobility has not yet been reneged upon, the set of "possible" types (those who have not yet imposed controls at $t$ ) evolves as a function of world interest rates. In each period, investors compare the cut-off type $\hat{x}_{t}$ to the current possible set $\left[\underline{x}_{t}, \infty\right]$, and update this set based on the observed policy. If controls are imposed, they will be in place forever after, and there is no more updating of information. If controls are not imposed, then this policy reveals that $x \geq \hat{x}_{t}$, and the posterior 
possible set becomes $\left[\underline{x}_{t+1}=\max \left\{\hat{x}_{t}, \underline{x}_{t}, \infty\right]\right.$. Interestingly, if the cut-off point falls below the possible set of types $\left(\hat{x}_{t} \leq \underline{x}\right)$, then no possible type imposes controls at $t$ : the equilibrium is of a pooling type, and a policy of free capital mobility is uninformative. Similarly in subsequent periods.

The evolution of the economy may also be described in terms of the path of interest rates. Suppose free mobility has prevailed in the host country in all previous periods. Define by $\hat{r}_{t}=\hat{r}_{t}\left(K_{t-1}, \underline{x}_{t}\right)$ the interest rate at which the worst possible type at time $t, \underline{x}_{t}$, is indifferent between imposing and not imposing controls in this period, given $K_{t-1}$ and the history of previous policies (summarized by $\underline{x}_{t}$ ). For $r_{t} \leq \hat{r}_{t}$, no possible type would impose controls, and a policy of free capital mobility is uninformative. For $r_{t}>\hat{r}_{t}$, types $x$ below the cut-off $\hat{x}_{t}$ impose controls, while types exceeding this cut-off do not: only interest rates in this range allow investors to use the observed policy to refine their knowledge of the government faced in the host country.

We now proceed to derive these properties more precisely in the next section.

\section{Technical Solution}

The model can be solved recursively backward, beginning with a closed-form solution for period $T$. We focus directly on market equilibrium conditions, and obtain a unique equilibrium for each period $t$ given the solution for period $t+1$. We adopt a standard equilibrium concept, that of Perfect Bayesian Equilibrium, which requires each agent's choice to be optimal given his beliefs and other agents' actions and beliefs, and that beliefs be updated in each period according to Bayes' rule, whenever this applies (i.e., whenever the probability of the conditioning event is not zero). (See Persson and Tabellini, 1990, for a detailed discussion, also in relation to other equilibrium concepts adopted in the macroeconomic signaling literature.) 
3.1. Period T: Investors' Policy. With free capital mobility, profit maximization equalizes the marginal returns from offshore and onshore investment at $T$. These are given by $R_{T}=1+r_{T}$, and $V_{T}=1+f^{\prime}\left(K_{T}\right)$, respectively, which include principal and scrap value of a unit of capital at the end of the period. Discounting returns at the rate $\frac{1}{1+r_{T}}$, the stock of capital invested onshore is $K_{T}^{*}\left(r_{T}\right) \equiv\left(f^{\prime}\right)^{-1}\left(r_{T}\right)$, decreasing in $r_{T}$ due to the concavity of $f($.$) .$

If capital controls are in place at $T$, instead, investors may be unable to attain the profitmaximizing solution, as the domestic stock of capital must satisfy the constraint $K_{T} \geq K_{T-1}$. For $r_{T} \leq f^{\prime}\left(K_{T-1}\right)$, controls are not binding, and the unconstrained solution prevails; for $r_{T}>f^{\prime}\left(K_{T-1}\right)$, instead, controls are binding, and the corner solution $K_{T}=K_{T-1}$ prevails.

3.2. Period T: Government's Policy. The government's optimal policy can be studied by characterizing the trigger type $\hat{x}_{t}=\hat{x}_{T}\left(K_{T-1}, r_{T}\right)$ that is just indifferent between imposing and not imposing controls at $T$ when $r_{T}>f^{\prime}\left(K_{T-1}\right)$, conditional on having not previously imposed controls. $\hat{x}_{T}$ is the unique solution for $x$ of the equation

$$
\rho\left[W\left(K_{T} \mid c_{T}=\mathrm{R}\right)-x-W\left(K_{T} \mid \mathrm{F}\right)\right]=0, \quad r_{T}>f^{\prime}\left(K_{T-1}\right)
$$

where, recall, $\rho$ is the government's discount factor. Equation (1) implies

$$
\hat{x}_{T}\left(K_{T-1}, r_{T}\right)=W\left(K_{T-1}\right)-W\left(\left(f^{\prime}\right)^{-1}\left(r_{T}\right)\right)
$$

The trigger $\hat{x}_{T}=\hat{x}_{T}\left(K_{T-1}, r_{T}\right)$ is a continuous and increasing function of $K_{T-1}$ and $r_{T}$, and governments imposing capital controls are those for which $x<\hat{x}_{T}$. These are intuitive properties: with a sufficiently high offshore rate, free capital mobility would lead to a capital outflow, thus tempting the government to impose controls. This temptation is stronger the larger is the amount 
of capital $K_{T-1}-K_{T}^{*}\left(r_{T}\right)$ that can be potentially trapped onshore, and, therefore, the higher are either $K_{T-1}$ or $r_{T}$. Free capital mobility prevails when the cost of imposing controls $x$ is sufficiently high to outweigh the utility gain from trapping capital onshore.

The nature of the equilibrium in period $T$ then depends on policies realized up to time $T$. As noted above, if capital controls have been imposed at any time prior to $T$, they are also imposed at $T$, irrespective of the specific value of $\hat{x}_{T}$ : there is no further cost in imposing controls at $T$, but this policy maximizes the period $T$ capital stock when $r_{T}>f^{\prime}\left(K_{T-1}\right)$. (Without loss of generality, we assume that when indifferent between imposing and not imposing controls, governments maintain the policy chosen in the previous period).

If free capital mobility has prevailed until $T$, instead, the form of the equilibrium depends on the relationship between $\hat{x}_{T}$ and the set of types that may have chosen such policy, given the observed path of world interest rates. As we shall see shortly, this set has the form of an interval $\left[\underline{x}_{T}, \infty\right]$. Accordingly, if $\hat{x}_{T} \leq \underline{x}_{T}$, a pooling equilibrium without controls prevails: the world interest rate is not sufficiently high to trigger a capital outflow sufficient to justify controls, even for the lowest possible type, $\underline{x}_{T}$. If $\hat{x}_{T}>\underline{x}_{T}$, instead, then a separating equilibrium prevails: types in the range $\left[\underline{x}_{t}, \hat{x}_{T}\right)$ impose controls; types in the range $\left[\hat{x}_{T}, \infty\right]$ allow free capital mobility.

Equilibria in periods $t<T$ will exhibit very similar properties, with the added feature that separating equilibria allow investors to truncate a set of types from the current possible set.

3.3. Period $t$ equilibrium. In each period $t$, investors compute the expected returns from onshore investment by considering the likelihood that capital controls may be imposed in the future. If controls are in place in period $t$, they will certainly be in place in the future as well. If controls are not in place at $t$, instead, the likelihood of future controls depends on investors' current 
beliefs over government types. These beliefs are fully summarized by the set of types that are possible at time $t$, i.e., those types that may have allowed free mobility until $t$. Our first task, accomplished by Proposition 1 , is to show that this set is described by a range $\left[\underline{x}_{t}, \infty\right]$, the convexity of which reflects the trigger nature of government policies in each period. In order to prove Proposition 1, we must first set up the government's problem in period $t$.

Consider type $x$ 's decision at $t$, and denote its utility from pursuing the policy $c_{t} \in\{\mathrm{F}, \mathrm{R}\}$

as

$$
\Psi_{t}\left(K_{t-1}, r_{t}, c_{t}, \underline{x}_{t}, x\right) \equiv \mathrm{E}_{t} \sum_{s=t}^{T} \rho^{s-t+1} W\left(K_{s} \mid c_{t}\right)-\mathrm{E}_{t} \sum_{s=t}^{T} \rho^{s-t+1} x \mathrm{I}\left(K_{s} \mid c_{t}\right),
$$

where $I($.$) is an indicator function that takes the value of one the first time controls are imposed,$ and zero otherwise; and the expectations are taken over $\left\{r_{i+1}, \ldots, r_{T}\right\}$ and over the corresponding contingent strategies chosen by $x$ at every node.

The choice of a government $x$ that has not previously imposed controls is whether or not to impose controls in the current period $t$, given $K_{t-1}, r_{t}$, and $\underline{x}_{t}$. Type $x$ 's gain from reneging at time $t$ on its commitment to free capital mobility, rather than postponing any such decision to a future period, is

$$
\psi_{t}\left(K_{t-1}, r_{t}, c_{t}=\mathrm{R}, \underline{x}_{t}, x\right)-\psi_{t}\left(K_{t-1}, r_{t}, c_{t}=\mathrm{F}, \underline{x}_{t}, x\right)
$$

Type $x$ imposes controls for the first time, in the first period for which this difference becomes positive. Proposition 1 shows that if a type $x$ chooses not to impose controls at $t$, then every higher type would do the same:

Proposition 1: If type $x^{\prime}$ does not impose controls at $t$, neither does any type $x^{\prime \prime}>x^{\prime}$.

Proposition 1 (whose proof is in Appendix) is intuitive: if $x^{\prime}$ chooses to postpone the time 
it first imposes controls, so would $x^{\prime \prime}$, whose cost-saving from such postponement is higher, and direct utility gain is at least as large. Proposition 1 allows us to summarize governments' policy in each period by a trigger rule, whereby types lower than a cut-off $\hat{x}_{t}=\hat{x}_{t}\left(K_{t-1}, r_{t}, \underline{x}_{t}\right)$ impose controls at $t$, if they have not previously imposed controls, while types exceeding $\hat{x}_{t}$ do not, unless they have previously imposed controls. The cut-off type $\hat{x}_{t}$ is defined as the lowest type not to impose controls at $t$. Being indifferent between imposing and not imposing controls at $t$, $\hat{x}_{i}$ satisfies $\psi_{t}\left(K_{t-1}, r_{t}, \mathrm{R}, \underline{x}_{t}, \hat{x}_{t}\right)-\psi_{t}\left(K_{t-1}, r_{t}, \mathrm{~F}, \underline{x}_{t}, \hat{x}_{t}\right) \equiv 0$, identically.

To solve investors' problem, first note that the expected marginal return from investing offshore at $t$, denoted by $R_{t}$, includes the current interest rate $r_{t}$, as well as the discounted expectation of future returns to being offshore at $t+1, R_{t}=\frac{r_{t}+\mathrm{E}_{t}\left[R_{t+1}\right]}{1+r_{t}}$.

Based on the trigger nature of government policies implied by Proposition 1, we can formalize investors' inference problem by means of a conditional distribution $\mathrm{G}\left(x \mid c_{t}, \hat{x}_{t}, \underline{x}_{t}\right)$ cumulated over types up to the unique cut-off for period $t+1, \hat{x}_{t+1}$. The expected marginal return from investing onshore in period $t, V_{t}$, can then be expressed as a function of current returns and a continuation value function for period $t+1$ returns, as

$$
\begin{aligned}
V_{t}\left(K_{t}, r_{t}, c_{t}, \hat{x}_{t}, \underline{x}_{t}\right) & =\frac{f^{\prime}\left(K_{t}\right)+\mathrm{E}_{t}\left[R_{t+1}\right] \operatorname{Pr}\left(c_{t+1}=\mathrm{F} \mid c_{t}, \hat{x}_{t}, \underline{x}_{t}\right)+\operatorname{Pr}\left(c_{t+1}=\mathrm{R} \mid c_{t}, \hat{x}_{t}, \underline{x}_{t}\right) \cdot \mathrm{E}_{t}\left[V_{t+1} \mid c_{t}, \hat{x}_{t}, \underline{x}_{t}\right]}{1+r_{t}} \\
& =\frac{f^{\prime}\left(K_{t}\right)+\mathrm{E}_{t}\left[R_{t+1}\right]-\mathrm{E}_{t}\left[R_{t+1}-V_{t+1}\left(K_{t}, r_{t+1}, \mathrm{R}\right)\right] \operatorname{Pr}\left(c_{t+1}=\mathrm{R} \mid c_{t}, \hat{x}_{t}, \underline{x}_{t}\right)}{1+r_{t}} \\
& =\frac{f^{\prime}\left(K_{t}\right)+\mathrm{E}_{t}\left[R_{t+1}\right]}{1+r_{t}}-\int_{r_{t+1}} \frac{R_{t+1}-V_{t+1}\left(K_{t}, r_{t+1}, \mathrm{R}\right)}{1+r_{t}} \mathrm{G}\left(\hat{x}_{t+1}\left(K_{t}, r_{t+1}\right) \mid c_{t}, \hat{x}_{t}, \underline{x}_{t}\right) \mathrm{d} \mathrm{M}\left(r_{t+1}\right),
\end{aligned}
$$

where the notation for $V_{t+1}$ reflects its independence of $\hat{x}_{t+1}$ and $\underline{x}_{t+1}$ when $c_{t+1}=\mathrm{R}$, since in this case controls become certain in all future periods. 
In (5), the cumulative distribution $\mathrm{G}\left(\hat{x}_{t+1} \mid c_{t}, \hat{x}_{t}, \underline{x}_{t}\right)$ is the probability of controls in period $t+1$ conditional on policies observed up to period $t$. Clearly, if $c_{t}=\mathrm{R}$, then $\mathrm{G}\left(\hat{x}_{t+1} \mid c_{t}=\mathrm{R}, \hat{x}_{t}, \underline{x}_{t}\right)$ equals one: as soon as controls are imposed, the type is revealed to lie in the range $\left[\underline{x}_{t}, \hat{x}_{t}\right)$, and the likelihood of controls in all subsequent periods becomes unity.

The case where $c_{t}=\mathrm{F}$ is more interesting for our purposes. If $\hat{x}_{t} \leq \underline{x}_{t}$ (that is, if all possible types allow free capital mobility at $t)$, then the distribution $\mathrm{G}\left(\hat{x}_{t+1} \mid c_{t}=\mathrm{F}, \hat{x}_{t}, \underline{x}_{t}\right)$ conditional on no controls before period $t$, collapses into the distribution $\mathrm{G}\left(\hat{x}_{t+1} \mid c_{t-1}=\mathrm{F}, \hat{x}_{t-1}, \underline{x}_{t-1}\right)$ conditional on no controls before period $t$-1. (For period one, this is the unconditional distribution G(.).)

If $\hat{x}_{t}>\underline{x}_{t}$, instead, the probability of $c_{t+1}=\mathrm{R}$ is obtained by Bayes' rule as

$$
\mathrm{G}\left(\hat{x}_{t+1} \mid c_{t}=\mathrm{F}, \hat{x}_{t}, \underline{x}_{t}\right)=\frac{\mathrm{G}\left(\hat{x}_{t+1}\right)-\mathrm{G}\left(\underline{x}_{t+1}\right)}{1-\mathrm{G}\left(\underline{x}_{t+1}\right)}
$$

for states $r_{t+1}$ where $\hat{x}_{t+1}>\underline{x}_{t+1}$, and as $\mathrm{G}\left(\hat{x}_{t+1} \mid c_{t}=\mathrm{F}, \hat{x}_{t}, \underline{x}_{t}\right)=0$ for states $r_{t+1}$ where $\hat{x}_{t+1} \leq \underline{x}_{t+1}$. (Recall that viewed from period $t, \hat{x}_{t+1}$ is a random variable that depends on the yet unknown $r_{t+1}$.) Furthermore, since the choice $c_{t}=\mathrm{F}$ reveals the true type to lie in the range $\left[\hat{x}_{t}, \infty\right]$, then $\underline{x}_{t+1}=\hat{x}_{t}$ in (6): the distribution $\mathrm{G}\left(\hat{x}_{t+1} \mid c_{t}, \hat{x}_{t}, \underline{x}_{t}\right)$ and the cut-off $\underline{x}_{t}$ evolve as a function of $r_{t}$, as investors truncate from the "possible" set, types that could not have chosen the observed policy.

Now denote by $K_{t}^{*}\left(r_{t}, c_{t}, \hat{x}_{t}, \underline{x}_{t}\right)$ the (unconstrained) profit-maximizing capital stock, defined as the solution for $K_{t}$ of

$$
R_{t}=V_{t}\left(K_{t}, r_{t}, c_{t}, \hat{x}_{t}, \underline{x}_{t}\right)
$$

Given either $c_{t}=\mathrm{F}$ or $c_{t}=\mathrm{R}, V_{t}$ is a continuous function of $K_{t}$ and $r_{t}$, going from infinity for $K_{t} \rightarrow 0$ to zero for $K_{t} \rightarrow \infty$. It is also apparent from (5) and (6) that if $\hat{x}_{t+1}$ is increasing in $K_{t}$ (which is true for $t=T$, and is shown to be true at $t$, recursively, in Proposition 2) then $R_{t}-V_{t}$ is 
increasing in $K_{t}$. Therefore, (7) yields a unique solution for the unconstrained profit-maximizing capital stock, $K_{t}^{*}\left(r_{t}, c_{t}, \hat{x}_{t}, \underline{x}_{t}\right)$, and Proposition 2 holds (proof is in the Appendix):

Proposition 2: $\hat{x}_{t}$ is increasing in $K_{t-1}$ and in $r_{t}$.

Propositions 1 and 2 have an important corollary: $\left(\underline{x}_{t}, \hat{x}_{t}\right]$ may be empty, that is, there may be interest rates $r_{t}$ so low, that no possible type switches from free mobility to controls at $t$. To see this, define by $\hat{r}_{t}=\hat{r}_{t}\left(K_{t-1}, \underline{x}_{t}\right)$ the interest rate that satisfies $\psi_{t}\left(K_{t-1}, \hat{r}_{t}, \mathrm{R}, \underline{x}_{t}, \underline{x}_{t}\right)-$ $\Psi_{t}\left(K_{t-1}, \hat{r}_{t}, \mathrm{~F}, \underline{x}_{t}, \underline{x}_{t}\right) \equiv 0$ identically. ${ }^{\prime \prime}$ At $\hat{r}_{t}$, the worst possible type at time $t, \underline{x}_{t}$, is indifferent between imposing and not imposing controls, given $K_{t-1}$. At $\hat{r}_{t}$ and at lower rates, no government that had not previously imposed controls would impose controls. Thus, for $r_{t} \leq \hat{r}_{t}$, the policy observed in period $t$ does not help investors refine their knowledge of government types and, hence, their forecast of future returns to investment.

Equations (5) and (7) also imply that any rise in $\mathrm{G}\left(\hat{x}_{t+1}\left(K_{t}, r_{t+1}\right) \mid c_{t}, \hat{x}_{t}, \underline{x}_{t}\right)$ (that is, any increase in the conditional probability of low government types) reduces the expected returns to $K_{t}$ and hence $K_{t}^{*}$ itself (formally, $K_{t}^{*}\left(r_{t}, \mathrm{~F}, \hat{x}_{t}, \underline{x}_{t}\right)>K_{t}^{*}\left(r_{t}, \mathrm{R}, \hat{x}_{t}, \underline{x}_{t}\right)$ ). Combined with Proposition 1 and with the effect of capital controls on investors' ability to withdraw capital from the host country, this implies that $K_{t}=K_{t-1}$ with controls, and $K_{t}=K_{t}^{*}\left(r_{t}, c_{t}=\mathrm{F}, \hat{x}_{t}, \underline{x}_{t}\right)$ with free capital mobility. Indeed, for $\hat{x}_{t}>\underline{x}_{t}$, controls must be binding at $t$ (that is, $K_{t}=K_{t-1}$ ): no government would renege on its commitment to free capital mobility unless controls are binding. Imposing controls implies a direct $\operatorname{cost} x$ and, by Proposition 1, (5), and (7), also a reputational cost of revealing the government to be of a type lower than $\hat{x}_{t}$

\footnotetext{
${ }^{11}$ The properties of $V_{t}$, noted above, and the assumed regularity of $W($.$) assure that \hat{r}_{t}$ is a well defined interest rate between 0 and $\infty$.
} 
Finally, note that as long as the probability of controls at $t+1, \mathrm{G}\left(\hat{x}_{t+1}\left(K_{t}, r_{t+1}\right) \mid c_{t}, \hat{x}_{t}, \underline{x}_{t}\right)$, is greater than zero, then Equation (5) incorporates a "political premium" which compensates investors for the possibility of future controls. This premium arises because with capital controls and high realizations of $r_{t}$, the return to investing onshore would fall below the expected return to investing offshore. In order to offset this potential loss (i.e., in order to equalize the present discounted streams of expected returns $R_{t}$ and $V_{t}$ ), risk-neutral investors require the current return to onshore investment, $f^{\prime}\left(K_{t}\right)$, to exceed the current return to offshore investment, $r_{t}$, before investing onshore. Thus, as long as $\mathrm{G}\left(\hat{x}_{t+1}\left(K_{t}, r_{t+1}\right) \mid c_{t}, \hat{x}_{t}, \underline{x}_{t}\right)>0$, then $\int_{r_{t+1}}\left(R_{\mathrm{r}+1}-V_{t+1}\left(K_{t}, r_{t+1}, \mathrm{R}\right)\right) \mathrm{d} \mathrm{M}\left(r_{t+1}\right)>0$ and Equations (5) and (7) imply that $f^{\prime}\left(K_{t}\right)>r_{t}$ for $c_{t}=\mathrm{F}$. The wedge $f^{\prime}\left(K_{t}\right)-r_{t}$ is our model's analog of the "political" premium identified empirically by Dooley and Isard (1980) and subsequent related studies.

\section{Learning from Observed Policies and the Effect of Interest Rate Shocks}

The model's equilibrium in period $t$, illustrated in Figure 2, can be summarized as follows. In each period following a history of free capital mobility, world interest rates can take values over two ranges, which depend on the policy history and on the existing capital stock: a low range $r_{t} \leq \hat{r}_{t}$, where all possible types of governments (i.e., those types whose cost of controls is consistent with not having imposed controls up to period $t$ ) allow unrestricted capital flows; and, a high range $r_{t}>\hat{r}_{t}$, where low $x$ types impose controls (thereby trapping $K_{t-1}-K_{t}^{*}\left(r_{t}, \mathrm{R}, \hat{x}_{t}, \underline{x}_{t}\right)$ ), while high $x$ types allow free capital mobility. Only for these interest rates is the observation of policies informative, in that it allows investors to refine their perception of government types, and hence improve their forecast of future policies and returns to investment. This split of interest rates into "high" and "low" ranges has interesting implications for policies and investment in 
individual countries, and for the efficiency of capital allocation across countries. We begin by discussing the former.

Figure 2 plots the inherited capital stock, $K_{t-1}$, and the desired capital stock in period $t$ as a function of the world interest rate $r_{t}$, both with free and restricted capital mobility. The desired stock conditional on free mobility, $K_{t}^{*}\left(r_{t}, \mathrm{~F}, \hat{x}_{t}, \underline{x}_{t}\right)$, lies above its restricted mobility counterpart, $K_{t}^{*}\left(r_{t}, \mathrm{R}, \hat{x}_{t}, \underline{x}_{t}\right)$, for each $r_{t}$ in the range of interest rates $\left[\hat{r}_{t}, \infty\right]$ that supports a separating equilibrium. This wedge reflects the discrete upward revision in investors' beliefs over government types, triggered by the observation of free capital mobility in period $t$ (which allows investors to truncate the set of possible types to the range $\left[\hat{x}_{t}, \infty\right]$ ), and the associated revision in expected returns to $K_{t}$. Conversely in response to the imposition of controls.

Note that the existing stock $K_{t-1}$ intersects the free-mobility curve at $r_{t}^{0}$, to the left of $\hat{r}_{t}$ : no government imposes controls unless they are strictly binding. In fact, there are two reasons why $r_{t}^{\circ}<\hat{r}_{t}$. First, capital controls entail a cost $x>0$ : prospective outflows must then exceed a minimum amount, before a government decides to incur their cost. A signaling motive associated to investors' incomplete information over governments also contributes to $r^{\circ}<\hat{r}_{1}$ : it is to a government's advantage to tolerate a larger outflow of capital than with common knowledge of its type, so as to provide to investors more favorable information on future business conditions in the host country. Thus, some governments allow free capital mobility in situations where they would have imposed controls had their type been known to investors, to mimic better types and signal their difference from worse types. Incomplete information about governments' attitudes toward capital controls provides a bias toward liberal capital markets. ${ }^{12}$

${ }^{12}$ A formal argument for this signaling result could be given. We omit details, however, as our focus is on the evolution of information on future policies over time, rather than on policy 
Consider now the effects of an interest rate in the "separating" range $r_{t}>\hat{r}_{t}$. If the host government liberalizes capital flows, an outflow $K_{t-1}-K_{t}^{*}\left(r_{t}, \mathrm{~F}, \hat{x}_{t}, \underline{x}_{t}\right)$ occurs at $t$. With capital controls, instead, an amount $K_{t-1}-K_{t}^{*}\left(r_{t}, \mathrm{R}, \hat{x}_{t}, \underline{x}_{t}\right)$ of capital is trapped onshore, as $K_{t}=K_{t-1}$. In this case, however, the separating nature of the equilibrium allows investors to sharpen their knowledge of the host government, by restricting its possible type to the range $\left[\underline{x}_{t}, \hat{x}_{t}\right]$ in the case of controls, and to the range $\left[\hat{x}_{t}, \infty\right]$ in the case of free mobility. In the former case, the probability of future controls conditional on $c_{t}=\mathrm{R}$ rises (to unity, in our simple model) with respect to its prior probability, while the probability of future controls conditional on $c_{t}=\mathrm{F}$ falls. By allowing free capital mobility, governments in the range $\left[\hat{x}_{t}, \infty\right]$ can build their reputation for aversion to capital controls. This signal is costly in the current period (a capital outflow must be tolerated), but it raises the desired capital stock in each future period, allowing capital inflows in states where capital outflows would have otherwise occurred. ${ }^{13}$

What happens, instead, when the interest rate $r_{t}$ is lower than $\hat{r}_{f}$ ? Now all possible types allow free capital mobility, and capital flows equal $K_{t}^{*}\left(r_{t}, \mathrm{~F}, \hat{x}_{t}, \underline{x}_{t}\right)-K_{t-1}$ (positive when $r_{t}<r_{t}^{\circ}$, and negative when $r_{t}^{0}<r_{t}<\hat{r}_{t}$ ). No information on future policies is revealed to investors. ${ }^{14}$

This solution has implications for the pattern of capital flows across countries in response

biases at any given time. Bartolini and Drazen (1995) further discuss these issues, though in the context of a model with a different information structure.

${ }^{13}$ Specifically, in each period $t, K_{t}^{*}\left(r_{t}, \mathrm{~F}, \hat{x}_{t}, \underline{x}_{t}\right)$ is higher than it would have been with controls replacing no controls in any previous period.

${ }^{14}$ Viewing the existence of separating and pooling equilibria in terms of high and low values of $r_{t}$ suggests a formalization of the notion that "tough" (that is, high $r_{t}$ ) times may benefit "tough" (that is, high $x$ ) types, by allowing these to separate themselves from weak types. The idea that information about future policies conveyed by current policies may depend on both the degree of uncertainty about a policymaker's type and the circumstances in which he finds himself was suggested by Drazen and Masson (1994). 
to interest rate shocks. Consider a world with two groups of economies: a large number of "emerging markets", i.e., small economies of the type described in Section 2, and the "rest of the world", where the supply of capital is elastic at the rate $r_{t}$ in each period. Suppose, for the moment, that all emerging markets are identical at the beginning of period $t$-1. (That is, let all of them be characterized by the same production technology, same prior distribution $\mathrm{G}(x)$ for government types, and same history of policies up to period $t$-1.) Under these assumptions, each country is exactly described by the model of Section 2 , and the critical value of $\hat{r}_{t-1}$ is the same for all countries. For illustration, consider the case of a period $t$ (the present) where the world interest rate is sufficiently low to spur a large inflow of capital into all emerging markets, thereby supporting a policy of widespread free capital mobility (i.e., $r_{t}<\hat{r}_{t}$ ). In this period, investors have the opportunity to allocate capital for maximum returns in period $t+1$ and onward (the future), in light of events observed up to period $t$-1 (the past).

Consider the impact of past interest rates on current investment, beginning with the case of a "low" rate at $t-1$, which we take as a stylized description of industrial countries' (mainly the U.S.') interest rates in the late 1980 s and, to an even greater extent, in the late 1970 s. The upper panel of Figure 3 gives an example of this pattern. (For simplicity, but with no relevance for our discussion, the figure displays $\hat{r}_{t-1}, \hat{r}_{t}$, and $\hat{r}_{t+1}$ as if these were the same).

If $r_{t-1} \leq \hat{r}_{t-1}$ and $r_{t} \leq \hat{r}_{t}$, then all countries allow free capital mobility at both $t-1$ and $t$, and (since all countries are identical a priori) receive the same investment flow at $t$, despite the underlying--but unobservable--difference in $x$ and in the likelihood of future controls: all-round liberalization at $t-1$ has destroyed the information content of the observed policy. For this outcome to obtain, investors need not believe the interest rate shock, nor the policy of free mobility, to be permanent. They know that a sufficiently high future interest rate will induce 
some countries to impose controls.

What happens if, indeed, the future interest rate, $r_{t+1}$, rises to above $\hat{r}_{t+1}$ ? First, the profitmaximizing stock of onshore capital falls, causing a desired outflow of capital from all emerging markets. Second, countries whose government assigns a relatively low cost to abandoning free capital mobility, impose controls on outflows. As a result, investors are trapped in some countries, earning a low rate of return. In our example, an amount of capital equal to $K_{t}^{*}\left(r_{t}, \mathrm{~F}, \hat{x}_{t}, \underline{x}_{t}\right)-K_{t+1}^{*}\left(r_{t+1}, \mathrm{R}, \hat{x}_{t+1}, \underline{x}_{t+1}\right)$ is trapped in countries with controls at $t+1$. Ex post, the world's allocation of capital is inefficient. In fact, this allocation is more inefficient (in the sense that a larger amount of capital is trapped in countries with controls) than it would be, had a separating equilibrium prevailed at $t-1$, a point that we now illustrate.

Consider an alternative interest rate path, where the interest rate at $t-1, r_{t-1}$, exceeds $\hat{r}_{t-1}$, and the rates at $t$ and $t+1$ remain the same as before (the bottom panel of Figure 3 illustrates this case). ${ }^{15}$ In this case, some governments impose controls at $t$-1, thus allowing investors to refine their prior information over government types: investors recognize types imposing controls as belonging to the range $\left[\underline{x}_{t-1}, \hat{x}_{t-1}\right)$, and those allowing free capital mobility as belonging to the range $\left[\hat{x}_{t-1}, \infty\right]$. When interest rates fall at $t$, high $x$ countries are rewarded with larger investment at $t$ than they would have been in our previous example, as their type as been narrowed to a smaller range $\left[\underline{x}_{t}, \infty\right]$. Low $x$ countries, their attempt to mimic higher types having been foiled at $t-1$, share to a smaller extent (or not at all) in the investment boom. ${ }^{16}$

${ }^{15}$ Strictly speaking, because $\hat{r}_{t}$ depends on $r_{t-1}$, we need $r_{t}$ to be lower than the $\hat{r}_{t}$ realized on both paths, and $r_{t+1}$ to be higher than the $\hat{r}_{t+1}$ realized on both paths for our illustrative discussion to remain valid.

${ }^{16}$ The extent of the fall in $r$, determines whether low- $x$ countries share in the investment boom. The assumed concavity of the onshore production function $f\left(K_{t}\right)$, in particular, implies that it is not optimal to direct all new flows to high- $x$ countries for sufficiently low rates $r_{t}$. 
When interest rates rise at $t+1$, an amount of capital $K_{t}^{*}\left(r_{t}, \mathrm{R}, \hat{x}_{t}, \underline{x}_{t}\right)-K_{t+1}^{*}\left(r_{t+1}, \mathrm{R}, \hat{x}_{t+1}, \underline{x}_{t+1}\right)$ (smaller than in the previous example, possibly nil), is trapped in low $x$ countries. More capital (reflecting the higher cut-off $\underline{x}_{t+1}$ overcome by these types) is invested in high $x$ countries. Thus, for a given $r_{t}$, a period $t$-1 interest rate above $\hat{r}_{t-1}$, enhances investors' ability to allocate capital efficiently at $t$, by investing less in low $x$ countries and more in high $x$ countries than when $r_{t-1}<\hat{r}_{t-1}$. No adjustment costs are needed for this information-based hysteresis property.

Similar results would hold in a more general model where emerging markets differ by production technology, prior distribution of $x$, or policy history. Countries endowed with more productive technologies would clearly attract more capital. The world interest rate that supports free capital mobility by all types would be country-specific, and the actual interest rate would have to be below the minimum of these for all countries to allow free capital mobility. If the prior distribution of types or policy history differs across countries, the analysis is similar and yields the country-specific triggers $\hat{x}_{t}$ and $\hat{r}_{t}$. Even if the interest rate in each period is so low that no country restricts capital movements, more capital is invested in countries whose prior distribution lies, roughly speaking, further to the right, as future controls are less likely in these countries. A sufficiently low world interest rate would cause all emerging markets to experience an inflow, with more capital being attracted to countries perceived as more averse to controls.

\section{More general specifications of the model}

A crucial assumption of the model that we have discussed is that imposing capital controls involves a one-time cost, an assumption which implies that controls, once imposed, are never lifted. This prediction is similar to that of many monetary games in the literature, where uncertainty about government taste for output and inflation causes some governments to choose 
zero inflation up to a certain time, only to revert to positive inflation forever after. Certainly, in the case of capital controls, this prediction is unrealistic.

Our motivation for choosing a simple cost structure was tractability and transparency of results. When a cost is incurred whenever controls are in place, the government's strategy space become too rich to permit a simple description of policies and of their response to shocks. Governments attaching higher costs to controls, for instance, may (counter-intuitively) impose controls earlier than low-cost governments, for the cost of discouraging investment early on, is offset by a reduced frequency of controls in the long run. In general, the properties of policies and investment become difficult to study, given the scope for complicated sequences of periods with and without controls, unless one commits to simple functional forms for $W(),. f(),. \mathrm{G}($.$) , and$ $\mathrm{M}($.$) or to other simplifying assumptions. One can still show that very low world interest rates$ would cause all possible governments to liberalize at any given time, thereby destroying the information content of a liberalization. At the opposite end, and as a more interesting implication of the more general model, very high interest rates would cause all possible governments to impose controls, thereby equally destroying the information content of the observed policy. Nevertheless, the more general model becomes almost untractable for intermediate interest rates, and multiple equilibria (among other complications) become possible for this range of rates.

One approach to addressing the unrealistic policies implied by our model, while retaining its tractability, is as follows. In every period up to time $T$, a government faces a probability $\alpha$ of being terminated (like a Blanchard-type consumer faces a positive probability of dying in each period) and of being replaced by another government drawn from the set $[\underline{x}, \bar{x}]$. A change in governments is common knowledge, but the new value of $x$ is not, as in our basic model. Thus, when a new government takes office, its choice problem and investors' inference problem begin 
anew. In particular, a new government faces the same problem faced at time zero in our basic model, and allows free capital mobility for sufficiently low interest rates or a sufficiently high $x$.

The formal structure of the extended model is very similar to that of our basic model. The solution for period $T$ remains identical, while the government's problem at $t<T$ is modified only by replacing the discount factor $\rho$ with $(1-\alpha) \rho$. Investors' inference problem becomes only slightly more difficult: the set of possible types in power is still truncated to $\left[\max \left\{\hat{x}_{t}, \underline{x}_{t}\right\}, \infty\right]$ in response to a policy of free capital mobility, but a probability $\alpha$ is attached to a new government coming to office and to the set of possible types being reset to $[\underline{x}, \bar{x}]$. Thus capital controls need not last forever, when imposed, but only until the next switch of government. ${ }^{17}$ The marginal return to onshore investment should also reflect the possibility of government turnover, as in

$$
\begin{aligned}
V_{t}\left(K_{t}, r_{t}, c_{t}, \hat{x}_{t}, \underline{x}_{t}\right)=f^{\prime}\left(K_{t}\right) & +\frac{\mathrm{E}_{t}\left[R_{t+1}\right]}{1+r_{t}}-\int_{r_{t+1}} \frac{R_{t+1}-V_{t+1}\left(K_{t}, r_{t+1}, \mathrm{R}\right)}{1+r_{t}} \\
\cdot & {\left[(1-\alpha) \mathrm{G}\left(\hat{x}_{t+1}\left(K_{t}, r_{t+1}\right) \mid c_{t}, \hat{x}_{t}, \underline{x}_{t}\right)+\alpha \mathrm{G}\left(\hat{x}_{t+1}\left(K_{t}, r_{t+1}\right) \mid \underline{x}\right)\right] \mathrm{d} \mathrm{M}\left(r_{t+1}\right) . }
\end{aligned}
$$

Propositions 1 and 2 hold unchanged in the extended model, and its qualitative properties, conditional on current governments remaining in office, also remain unchanged. In fact, the dependence of investment on the history of world interest rates persists beyond governments' lifetimes, via the stock of capital bequeathed from one government to the next. ${ }^{18}$

${ }^{17}$ In fact, government "changes" might be viewed, more broadly, as credible breaks with old policies, breaks often pursued by finance ministers at the onset of liberalization programs. Naturally, this broader interpretation should address the issue of what makes these policy breaks credible.

${ }^{18}$ In an even more general model, the probability of survival $1-\alpha$ would be itself endogenous to policies. In practice, we would expect the imposition of capital controls to have secondary and ambiguous effects on governments' survival, as capital controls typically harm the interest of some constituencies (e.g., investors) while benefitting those of others (e.g., wage-earners). 
Despite its somewhat ad hoc flavor, this extension does capture some interesting features of an extended model with government turn-over. It also highlights an important requirement for our model's insight to emerge: some amount of persistence in government types is necessary for information acquisition to matter at all in our model. In general, the faster is governments' turnover, the less relevant are observed policies to signal the course of future policies, while governments become less concerned with the adverse information impact of imposing capital controls. In the limit, if $\alpha=1$, then governments last for only one period; expected returns to onshore investment and the allocation of capital across countries become independent of past policies; and governments' decision problem collapses into a myopic one-shot problem.

Although lack of a closed-form solution when $\alpha>0$ prevents explicit comparative statics analysis, the vanishing of "bad-signal" effects as $\alpha \rightarrow 1$ (that is, the vanishing of $\mathrm{G}\left(\hat{x}_{t+1}\left(K_{t}, r_{t+1}\right) \mid c_{t}, \hat{x}_{t}, \underline{x}_{t}\right)$ from Equation (8)), suggests that governments with shorter horizon should be more likely to abandon free capital mobility than governments with a longer horizon.

Another approach to generalizing the basic model and incorporate more realistic costs of capital controls, would be to simplify drastically the state space for government types, for example, to two types, as is common in macroeconomic signaling models. Further assuming one of these two types to be a "hard-nosed" government irrevocably committed to free capital mobility (see Barro, 1986, and Backus and Driffill, 1985, for the equivalent assumption in the context of monetary policy games), $x$ can take two values, $x \in\{\underline{x}, \infty\}$, with probabilities $\mathrm{G}$ and $1-\mathrm{G}$, respectively, instead of all values in the interval $[\underline{x}, \infty]$. A payoff to this simplification is that we can let the cost of controls, $x$, to be incurred every time controls are imposed, while still obtaining a tractable model. Though we omit details, it is clear that until capital controls are imposed for the first time, investors face essentially the same inference problem as in our basic 
model. Investment still displays information-based hysteresis and, since low $x$ types always face a meaningful trade-off between controls and free capital mobility, this model produces a more realistic pattern of capital controls, with controls imposed and lifted in response to changes in world interest rates. The main cost of this simplification would be reversion to full information as soon as controls are imposed for the first time (for this policy identifies the government as a low $x$ type). In reality, however, one would not expect a government to last forever, and a combination of this and the previous model is likely to provide a reasonable characterization of actual policies. In spite of the difficulty of obtaining stronger results in a model that is both general and tractable, the insight that very favorable and very adverse external environments should make observed policies less informative of future policies (in that all governments tend to act uniformly in these circumstances), seems a robust one.

\section{Concluding Remarks}

Recent developments in capital flows from industrial to developing countries and in policies affecting international capital mobility, confirm a pattern emerged in recent decades, whereby liberal policies in developing countries have been implemented mainly during periods of low interest rates in industrial countries and large capital flows toward developing countries, and vice versa. In this paper we have presented a simple model of endogenous capital account policies to help rationalize these developments, and contribute to our understanding of the link between liberalizations and capital flows.

Analytically, our main results concern the link between the nature of the model's equilibrium and external shocks, taken here to be a world interest rate shock: "low" world interest rates support capital flows toward emerging markets and an equilibrium where all these 
countries allow free capital mobility; "high" interest rates support an equilibrium where countries with governments highly committed to liberal policies distinguish themselves by allowing free capital mobility, while countries with less committed governments trap capital onshore by imposing controls on capital outflows. In equilibrium, information on the likely course of future policies revealed to investors reflects the path of world interest rates: a period of low interest rates in industrial countries supports widespread adoption of free capital mobility, but prevents investors from discriminating among different policy environments. Should interest rates later rise, investors may find themselves as having invested too much in countries that were not truly committed to free capital mobility. This outcome is consistent with investors' recognizing the potential temporariness of external shocks and policies.

To sharpen our analysis, we focussed on a specific source of political risk: the imposition of restrictions on capital mobility in the wake of adverse external shocks. Though many would view capital controls as a primary source of political risk for international investors, we view our study only as a tackle to a more general issue: the link between the information content of structural reform and the macroeconomic environment. We feel, in particular, that our model's insight should extend beyond the case of capital controls, to situations where governments can undertake a variety of reforms, and have access to multiple signals of commitment to such reforms. When governments have private information on their utility from reform, and the cost of reform depends on the external environment, good times are likely to reduce these costs, lead to widespread reform, and diminish these policies' usefulness as signals of future policies; bad times are likely to lead to policy reversal, and to investors' regretting prior investment decisions. 


\section{Table 1. Time structure of the model}

time $=0: \quad$ - Inherited stock of capital, $K_{0}$.

- $x$ is drawn from $\mathrm{G}(x)$ and revealed only to the government.

time $=t \leq T:-r_{\imath}$ is drawn from $\mathrm{M}(r)$ and revealed

- Government chooses $c_{t} \in\{\mathrm{F}, \mathrm{R}\}$.

- Public chooses $K_{t}$ (with $K_{t} \geq K_{t-1}$ if $c_{t}=\mathrm{R}$ ) and collects profits.

\section{Appendix}

Proof of Proposition 1. We show that if $x^{\prime}$ chooses $c_{t}=\mathrm{F}$, then $x^{\prime \prime}$ also chooses $c_{t}=\mathrm{F}$, if $x^{\prime \prime}>x^{\prime}$ for two possible types at $t$, since $x^{\prime \prime}$ prefers to mimic $x^{\prime}$ 's strategy (including $c_{t}=\mathrm{F}$ ) than choosing $c_{t}=\mathrm{R}$ (and $c_{s}=\mathrm{R}, s>t$, thereafter). To see this, write type $x$ 's welfare function $\psi_{t}$ as

$$
\psi_{t}\left(K_{t-1}, r_{t}, c_{t}, \underline{x}_{t}, x\right) \equiv \tilde{W}_{t}(x)-\tilde{\rho}_{t}(x)
$$

where

$$
\tilde{W}_{t}(x) \equiv \mathrm{E}_{t} \sum_{s=t}^{T} \rho^{s-t+1} W\left(K_{s} \mid c_{t}\right), \quad \tilde{\rho}_{t}(x) \equiv \mathrm{E}_{t} \sum_{s=t}^{T} \rho^{s-t+1} x \mathrm{I}\left(K_{s} \mid c_{t}\right)
$$

and $\tilde{\rho}_{t}(x)<x$, since $\rho<1$ and the probabilities add to unity.

Now, let $x^{\prime}$ choose $c_{\mathrm{t}}=\mathrm{F}$, and compare the payoff to $x^{\prime \prime}$ from following $x^{\prime}$ 's contingent strategy, to that from imposing controls at $t$ and choosing $c_{s}=\mathrm{R}$ thereafter. We have:

$$
\begin{aligned}
\Psi_{t}\left(K_{t-1}, r_{t}, c_{t}=\mathrm{F}, \underline{x}_{t}, x^{\prime \prime} \mid \text { at } x^{\prime \prime} \text { s strategy }\right) & \\
\equiv \tilde{W}_{t}\left(x^{\prime}\right)-\tilde{\rho}_{t}\left(x^{\prime \prime}\right) & : x^{\prime} \text { 's strategy at } x^{\prime \prime} \text { 's cost } \\
\geq \tilde{W}_{t}\left(x^{\prime \prime}\right)-x^{\prime}+\tilde{\rho}_{t}\left(x^{\prime}\right)-\tilde{\rho}_{t}\left(x^{\prime \prime}\right) & \text { : by def. of } x^{\prime \prime} \text { s optimal policy }
\end{aligned}
$$




$$
\begin{array}{ll}
=\tilde{W}_{t}\left(x^{\prime \prime}\right)-x^{\prime \prime}+\left[\left(x^{\prime \prime}-x^{\prime}\right)-\tilde{\rho}_{t}\left(x^{\prime \prime}-x^{\prime}\right)\right] & : \text { by linearity of } \tilde{\rho}_{t}(.) \\
>\tilde{W}_{t}\left(x^{\prime \prime}\right)-x^{\prime \prime} & : \text { since } z>\tilde{\rho}_{t}(z), \forall z \\
\equiv \Psi_{t}\left(K_{t-1}, r_{t}, c_{t}=\mathrm{R}, \underline{x}_{t}, x^{\prime \prime}\right), & \text { : i.e., } x^{\prime \prime} \text { prefers } c_{t}=\mathrm{F} \text { to } c_{t}=\mathrm{R} .
\end{array}
$$

Proof of Proposition 2. First, simplify the notation by writing $\psi_{t}(\mathrm{R}) \equiv \psi_{t}\left(K_{t-1}, r_{t}, c_{t}=\mathrm{R}, \underline{x}_{t}, x\right)$ and $\psi_{t}(\mathrm{~F}) \equiv \Psi_{t}\left(K_{t-1}, r_{t}, c_{t}=\mathrm{F}, \underline{x}_{t}, x\right)$. To prove that $\frac{\partial \hat{x}_{t}}{\partial K_{t-1}}>0$, first note that $K_{t-1}$ enters (7) only through $\hat{x}_{t}$ in $\mathrm{G}($.$) . Hence, by total differentiation of (7) with respect to K_{t-1}$, the signs of $\frac{\partial K_{t}^{*}}{\partial K_{t-1}}$ and $\frac{\partial \hat{x}_{t}}{\partial K_{t-1}}$ must be the same; in particular, these two terms vanish for the same values of $K_{t^{-1}}$. (i.e., the desired capital stock responds to $K_{t-1}$ only if $K_{t-1}$ affects governments' decisions).

Now note that $K_{t-1}$ affects $\psi_{t}(\mathrm{R})-\Psi_{t}(\mathrm{~F})$ directly (and positively) through $K_{t-1}$ in $\psi_{t}(\mathrm{R})$, and indirectly (and ambiguously) through the effects of $K_{t}^{*}$ on $\hat{x}_{t+1}$ and $K_{t+1}, \ldots, K_{T}$ in $\psi_{t}(\mathrm{R})$ and $\psi_{t}(\mathrm{~F})$. Using these properties, we show that $\frac{\partial \hat{x}_{t}}{\partial K_{t-1}}>0$ in two steps.

i. First, $\frac{\partial \hat{x}_{t}}{\partial K_{t-1}}$ cannot change sign. To see this, assume the existence of a $\hat{K}_{t-1}$ where $\frac{\partial \hat{x}_{t}}{\partial K_{t-1}}=0$. Totally differentiate $\psi_{t}\left(K_{t-1}, r_{t}, \mathrm{R}, \underline{x}_{t}, \hat{x}_{t}\right)-\psi_{t}\left(K_{t-1}, r_{t}, \mathrm{~F}, \underline{x}_{t}, \hat{x}_{t}\right) \equiv 0$ with respect to $K_{t-1}$, and evaluate the results at $\hat{K}_{t-1}$. The terms involving $\frac{\partial K_{t}^{*}}{\partial K_{t-1}}$ vanish, since $\frac{\partial K_{t}^{*}}{\partial K_{t-1}}=\frac{\partial \hat{x}_{t}}{\partial K_{t-1}} \equiv 0$ at $\hat{K}_{t-1}$. Hence,

$$
\frac{\partial \Psi_{t}(\mathrm{R})}{\partial K_{t-1}}+\frac{\partial\left(\Psi_{t}(\mathrm{R})-\Psi_{t}(\mathrm{~F})\right)}{\partial \hat{x}_{t}} \cdot \frac{\partial \hat{x}_{t}}{\partial K_{t-1}}=0
$$

which, however, cannot hold, since the first term is positive, and $\frac{\partial \hat{x}_{t}}{\partial K_{t-1}}=0$ at $\hat{K}_{t-1}$.

ii. Finally, the sign of $\frac{\partial \hat{x}_{t}}{\partial K_{t-1}}$ is positive: no type would switch to controls when $K_{t-1}=0$, whereas all types would switch to controls when $K_{t-1} \rightarrow \infty$.

The proof that $\frac{\partial \hat{x}_{t}}{\partial r_{t}}>0$ is similar. We need only look at values of $r_{t}$ with binding controls. Assume the existence of a $\hat{r}_{t}$ where, with binding controls, $\frac{\partial \hat{x}_{t}}{\partial r_{t}}=0$. Total differentiation of 
$\psi_{t}\left(K_{t-1}, r_{t}, \mathrm{R}, \underline{x}_{t}, \hat{x}_{t}\right)-\Psi_{t}\left(K_{t-1}, r_{t}, \mathrm{~F}, \underline{x}_{t}, \hat{x}_{t}\right) \equiv 0$ with respect to $r_{t}$ shows that $\frac{\partial\left(\Psi_{t}(\mathrm{R})-\psi_{t}(\mathrm{~F})\right)}{\partial r_{t}}=0$ at $\hat{r}_{s}$. However, $\psi_{t}(\mathrm{R})$ is independent of $r_{t}$ in a neighborhood of $\hat{r}_{t}$ (where $K_{t}=K_{t-1}$ and $\left.\frac{\partial \hat{x}_{t}}{\partial r_{t}}=0\right)$. In contrast, $\Psi_{t}(\mathrm{~F})$ is decreasing in $r_{t}$. To see this note that $\frac{\partial K_{t}^{*}}{\partial \hat{r}_{t}}<0$ at $\hat{r}_{t}$ (see (5) and (6), using $\frac{\partial \hat{x}_{t}}{\partial r_{t}}=0$ at $\left.\hat{r}_{t}\right)$; hence, $\frac{\partial W\left(K_{t} \mid c_{t}=\mathrm{F}\right)}{\partial r_{t}}<0$ at $\hat{r}_{t}$. Furthermore, since $\frac{\partial \hat{x}_{t}}{\partial r_{t}}=0$ at $\hat{r}_{t}$, lower $r_{t}$ affects $K_{t+1}, \ldots, K_{T}$ only through a higher $K_{r}$; now, since the strategy followed starting from a lower $K_{t}$ can always be replicated starting from a higher $K_{t}$, then $W\left(K_{t+1} \mid c_{t}=\mathrm{F}\right), \ldots, W\left(K_{T} \mid c_{t}=\mathrm{F}\right)$ cannot fall as $K_{t}$ rises, i.e., as $r_{t}$ falls. Therefore, $\frac{\partial\left(\Psi_{t}(\mathrm{R})-\Psi_{t}(\mathrm{~F})\right)}{\partial r_{t}}>0$ at $\hat{r}_{t}$, showing that $\frac{\partial \hat{x}_{t}}{\partial r_{t}}$ cannot change sign. Finally, no type would switch to controls when $r_{t}=0$, whereas all types would switch to controls when $r_{t} \rightarrow \infty$. The sign of $\frac{\partial \hat{x}_{t}}{\partial r_{t}}$ must then be positive. 
Figure 1

G-7 Real Interest Rates and Developing Countries' Capital Controls Index

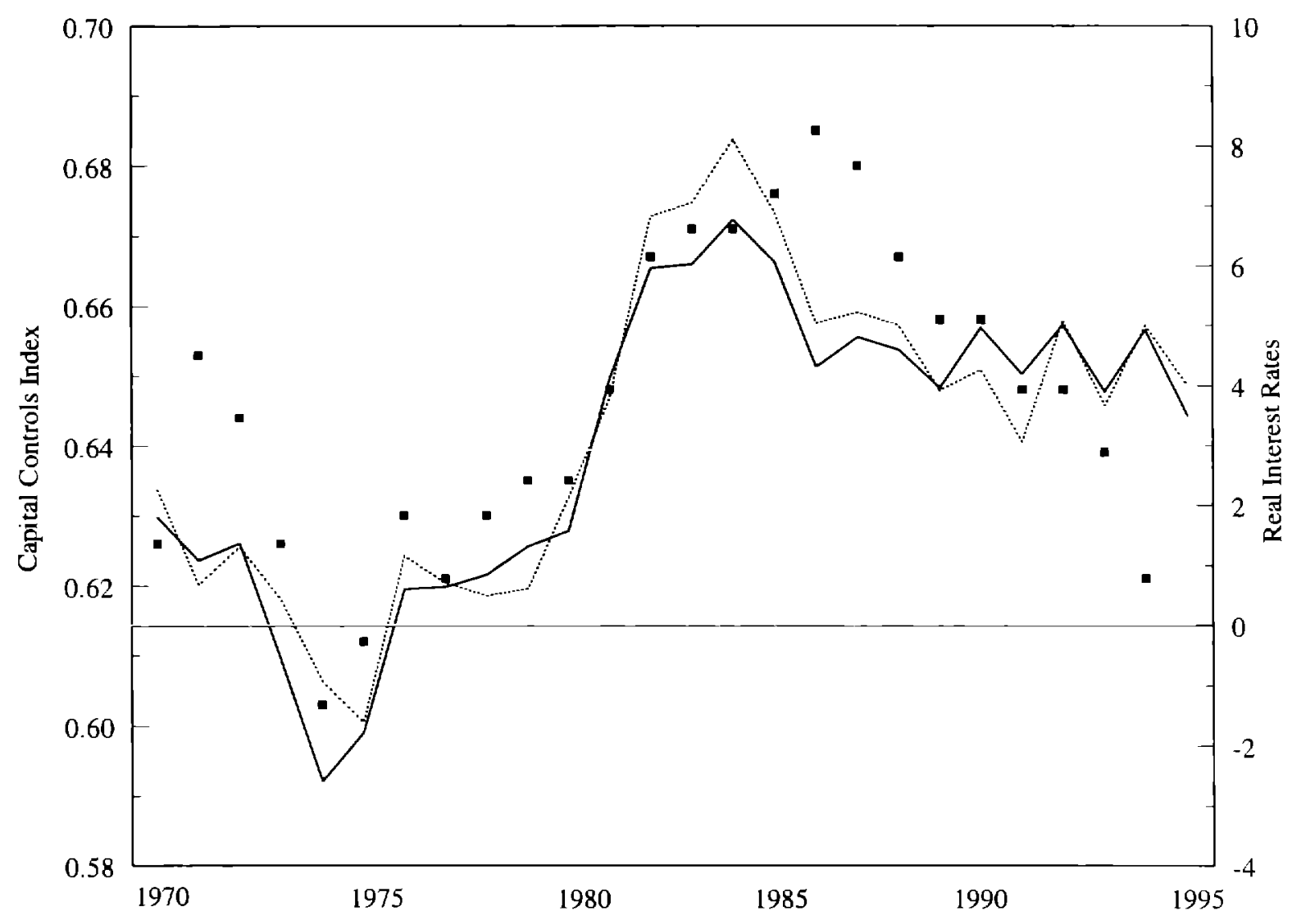

- Developing Countries' Capital Controls Index

G-7 Real Long-Term Interest Rate (annualized)

_ U.S. Real Long-Term Interest Rate (annualized) 
Figure 2

Equilibrium Onshore Investment

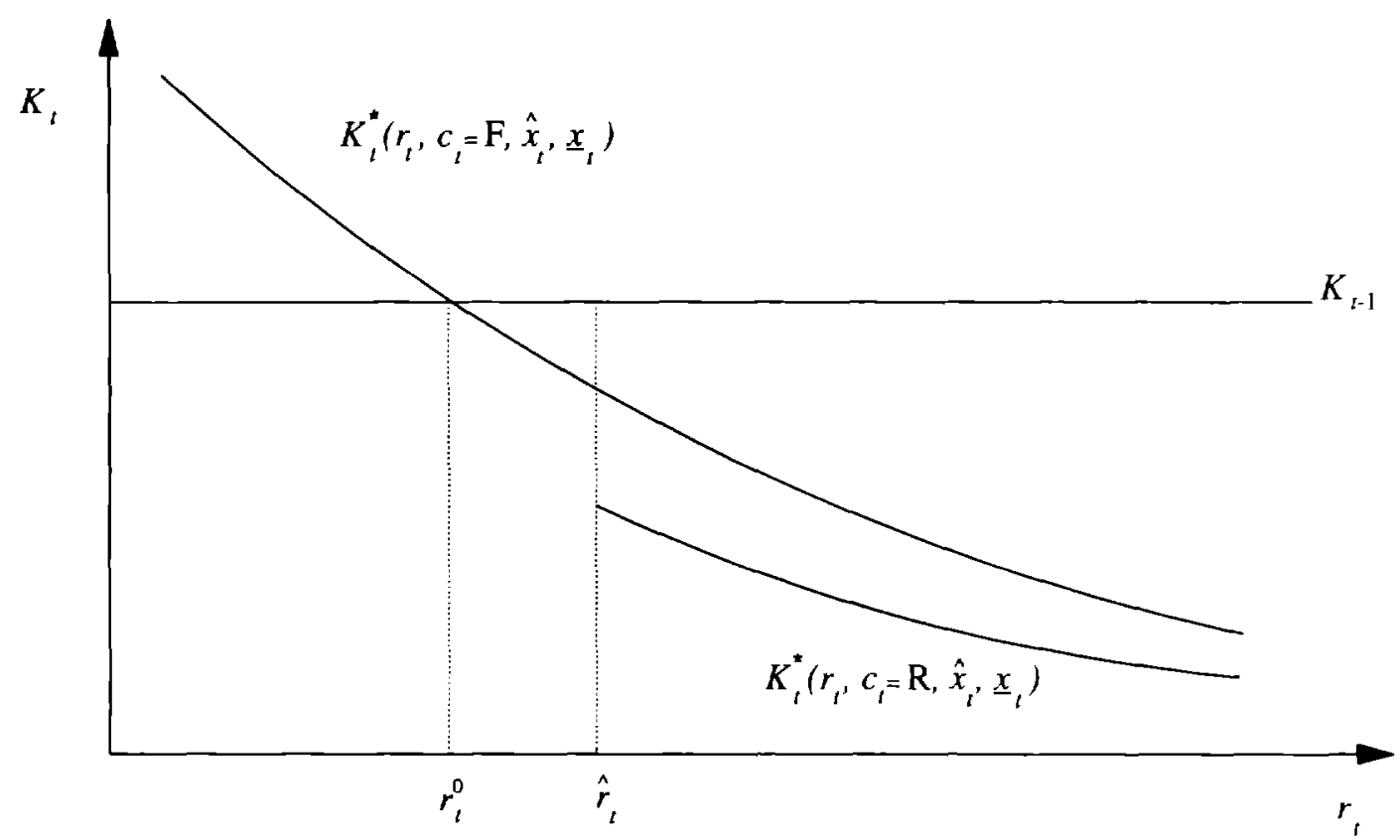


Figure 3

Patterns of World Interest Rates

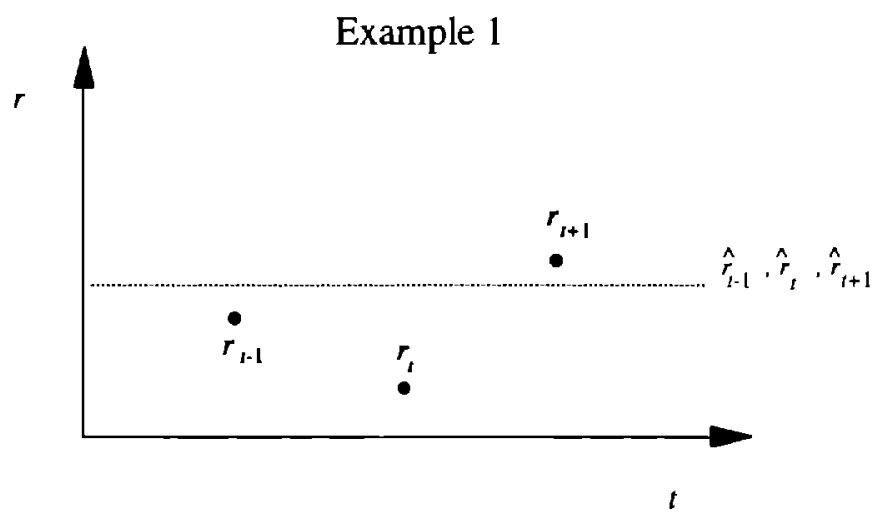

Example 2

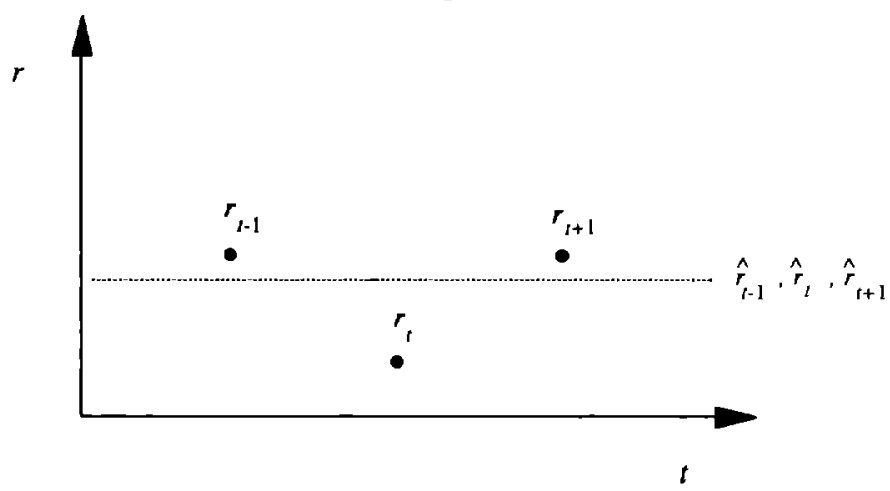




\section{References}

Bacchetta, P. (1992), Liberalization of Capital Movements and of the Domestic Financial System, Economica 59, 465-474.

Backus, D., and J. Driffill (1985), Inflation and Reputation, American Economic Review 75, 530538.

Barro, R. (1986), Reputation in a Model of Monetary Policy with Incomplete Information, Journal of Monetary Economics 17, 3-20.

Bartolini, L., and A. Drazen (1995), Capital Account Liberalization as a Signal, American Economic Review, forthcoming.

Calvo, G., L. Leiderman, and C. Reinhart (1993), Capital Inflows and Real Exchange Rate Appreciation in Latin America, IMF Staff Papers 40.1, 108-151.

Calvo, G., L. Leiderman, and C. Reinhart (1994), Capital Inflows to Latin America: With a Reference to the Asian Experience, in: S. Edwards, ed., Capital Controls, Exchange Rates, and Monetary Policy in the World Economy (Cambridge University Press, Cambridge).

Calvo, S., and C. Reinhart (1995), Capital Flows to Latin America: Is There Evidence of Contagion Effects? IMF, Washington, mimeo.

Chuhan, P., Claessens, S., and N. Mamingi (1993), Equity and Bond Flows to Latin America and Asia: The Role of External and Domestic Factors, The World Bank, mimeo.

Dooley, M., and P. Isard (1980), Capital Controls, Political Risk, and Deviations from Interest Parity, Journal of Political Economy 88, 370-384.

Drazen, A., and P. Masson (1994), Credibility of Policies Versus Credibility of Policymakers, Quarterly Journal of Economics 109, 735-754.

Epstein, G., and J. Schor (1992), Structural Determinants and Economic Effects of Capital Controls in OECD Countries, in: T. Banuri and J. Schor (eds.) Financial Openness and National Autonomy (Clarendon Press, Oxford).

Grilli, V., and G.M. Milesi-Ferretti (1995), Economic Effects and Structural Determinants of Capital Controls, IMF Staff Papers 42, 517-551.

IMF (1996), World Economic Outlook, May (IMF, Washington).

Mathieson, D.J., and L. Rojas-Suárez (1993), Liberalization of the Capital Account. Experiences and Issues, Occasional Paper No. 103 (IMF, Washington). 
Obstfeld, M. (1986), Capital Flows, the Current Account, and the Real Exchange Rate: The Consequences of Liberalization and Stabilization, in: S. Edwards and L. Ahamed, eds., Economic Adjustment and Exchange Rates in Developing Countries (Chicago).

Persson, T., and G. Tabellini (1990), Macroeconomic Policy, Credibility, and Policy (Harwood Academic Publishers, London).

Rogoff, K. (1987), Reputational Constraints on Monetary Policy, Carnegie-Rochester Conference Series on Public Policy 26, 141-181. 